\title{
A DFT Study on Selected Physical Organic Aspects of the Fischer Carbene Intermediates $\left[\left(\mathrm{M}(\mathrm{CO})_{4}(\mathrm{C}(\mathrm{OMe}) \mathrm{Me})\right]\right.$
}

\author{
TAREQ IRSHAIDAT \\ Department of Chemistry, College of Sciences, \\ Al-Hussein Bin Talal University, Ma'an, Jordan. \\ tirshaidat@yahoo.com
}

Received 19 August 2009; Accepted 10 October 2009

\begin{abstract}
Fischer carbenes are important starting materials for C-C bond formation via coupling reactions between carbene and wide variety of substituted alkenes or alkynes. This DFT study shed light on unique fundamental organic/organometallic aspects for the $\mathrm{C}(\mathrm{OMe}) \mathrm{Me}$ carbene in the free form and in case of bonding with $\mathrm{M}(\mathrm{CO})_{4}(\mathrm{M}=\mathrm{Cr}, \mathrm{Mo}, \mathrm{W})$. The data illustrate that the structures of the title intermediates include a unique structure stabilizing intramolecular M...C-H interaction (agostic interaction). This conclusion was made based on calculated NMR data (for carbon and hydrogen), structural parameters, energy calculations of conformers (C-C conformation), selected IR stretching frequencies (C-O, C-C, and $\mathrm{C}-\mathrm{H}$ ), and atomic charges. The agostic interaction is most efficient in case of chromium and in general is described as an overlap between the $\sigma$-bond electron pair of $\mathrm{C}-\mathrm{H}$ with an empty d-orbital of the metal. These characterized examples are new addition to the orbital interaction theory.
\end{abstract}

Keywords: Fischer carbene, DFT, Electronic structure, Group 6 transition metals, NMR, IR.

\section{Introduction}

One of the most important synthetic applications for Fischer carbenes is the benzannulation reaction involving the coupling of $\alpha, \beta$-unsaturated carbene complexes and alkynes, commonly known as the Dötz Reaction. This reaction results in the formation of phenols or naphthoquinones and proceeds with considerable regioselectivity when the substituents on the alkyne are distinctly different in size. This formal $[3+2+1]$ cycloaddition proceeds by sequential coupling of the alkyne, carbene and one carbonyl ligand at a $\mathrm{Cr}(\mathrm{CO})_{3}$ template. The proposed mechanisms of this reaction have been made based on experimental and theoretical studies (Figure 1). The sequence 1-2'-3-4-5-9-10 was proposed by Dötz $z^{1}$ and studied theoretically (DFT) by Hess, Dötz and Gleichmann ${ }^{2}$. Intermediates 7 and 8 were suggested by Casey ${ }^{3}$ and the sequence 1-2-4-6-9-10 was suggested and studied by means of density functional theory using a slightly higher level of theory by Solà ${ }^{4,5}$. The path proposed by Solà is the lowest in energy, 
however the theoretical studies indicated that the net reaction is exothermic. A correspondence published in the same year after Solà's study discussed Solà's results ${ }^{6}$. It was pointed out that the associative path (Figure 1) does not explain the regioselectivity reported for these reactions based on experimental data. A detailed experimental study provided by Barluenga and coworkers ${ }^{7}$ came later and supported the mechanistic sequence proposed by Dötz (1-2'-3-4-5-9-10). However, it seems that there is no definite mechanism yet which opens the door for further investigations and discussions among chemists interested in this area.

In general and as part of understanding chemical reactions, the organic reactive intermediates have been studied extensively, experimentally and theoretically. On the other hand, the organometallic versions have received much less attention ${ }^{8-10}$. Regarding the carbene coupling reaction, despite suggesting intermediate (2') since the last century but the literature lacks any details about its fundamental physical organic-organometallic aspects. Therefore, we devoted this effort to study the electronic structure of this intermediate (Figure 1). When $\mathrm{R}_{2}=$ Methyl (Me) the structure exhibits many interesting unique features. The details are presented here and will show that, in principle, the agostic interaction M...C-H in carbene complexes is possible (Figure 2).

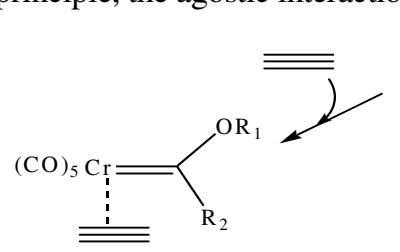

(2)

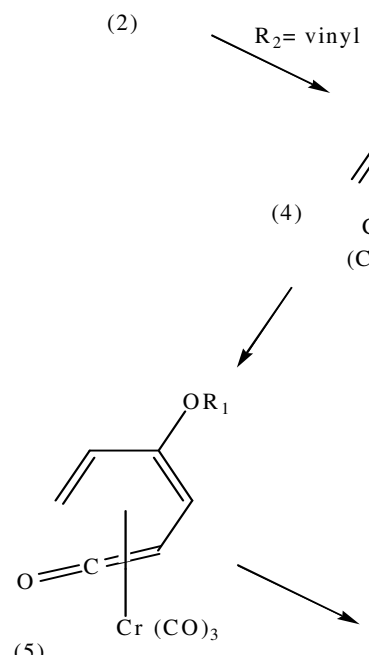

(5)

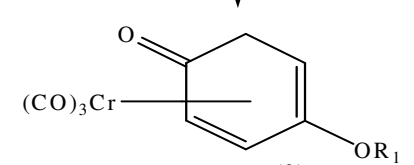

(9)

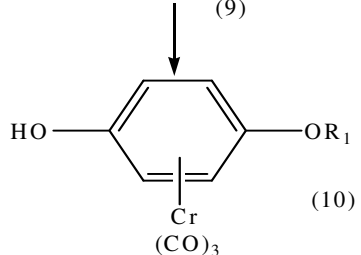

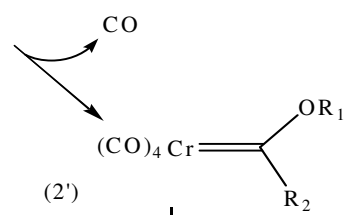

(3)<smiles>[R10]C([R2])=C(C#C)[Ge](=O)OC</smiles>

(6)

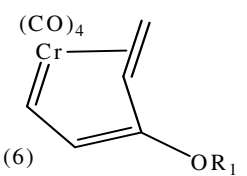<smiles>[R20]C1=CC[Ge](C(=O)O)C=C1</smiles>

(7)

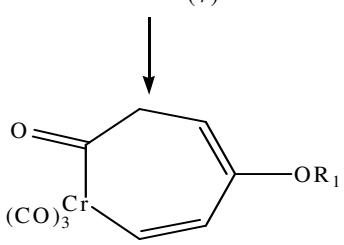

(8)

Figure 1. Proposed pathways for the benzannulation reaction (Dötz reaction). 


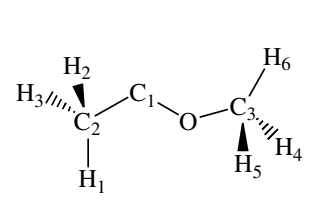

Free Carbene

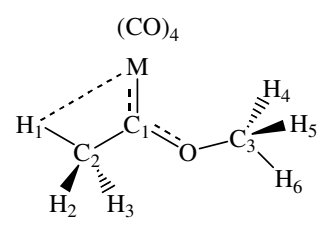

$\mathrm{M}=\mathrm{Cr}, \mathrm{Mo}, \mathrm{W}$<smiles></smiles>

Methyl Acetate

Figure 2. The numbering system used in this study.

\section{Experimental}

Our calculations were carried out using density functional theory (DFT) by using the Becke's three-parameter exchange functional in conjunction with the Lee-Yang-Parr correlation functional (B3LYP) ${ }^{11}$ level of theory as implemented in GAUSSIAN 03 suit of programs ${ }^{12}$. The basis set $6-31 \mathrm{G}(\mathrm{d})^{13}$ was assigned for the atoms $\mathrm{C}, \mathrm{H}$ and $\mathrm{O}$, while the Stuttgart-Dresden effective core potentials basis set (SDD) ${ }^{14}$ was assigned for the metals. All of the energy minimum structures showed positive eigen values of the Hessian matrix. Calculating the harmonic vibrational frequencies and noting the number of the imaginary frequencies confirmed the nature of all intermediates (number of imaginary frequencies $=0$ ). The thermodynamic functions, including entropies, enthalpies and the Gibbs free energies were calculated employing the usual approximations of statistical thermodynamics (ideal gas, harmonic oscillator, and rigid rotor) at the temperature of $298.15 \mathrm{~K}$ and the pressure of $1.00 \mathrm{~atm}$. The atomic charges were obtained from two schemes, the atom polarizability tensor scheme (APT charges) ${ }^{15}$ and the natural population analysis scheme (NPA charges) ${ }^{16}$. The NMR data were obtained by employing the GIAP method ${ }^{17}$ at the same level of theory, and TMS was considered the reference.

\section{Results and Discussion}

\section{Structural parameters}

The structural data (Table 1) allows extracting some valuable remarks about the nature of bonding between the carbene as a ligand and the metal. It is noticed that the $\mathrm{C} 1-\mathrm{O}$ bond is shorter in presence of $[\mathrm{M}]$. This indicates that this bond becomes stronger, which is explained in the following way. The specific change gives an idea about efficiency of the back donation from the metal to stabilize the empty $p$-orbital on $\mathrm{C} 1$. It is obvious that the carbene is strong $\sigma$-donor but the metal is weak $\pi$-donor (back donor). As a result, $\mathrm{C} 1$ becomes electron deficient and the charge compensation comes from the oxygen lone pairs as $\pi$-bond, which in turn decreases the $\mathrm{C} 1-\mathrm{O}$ bond length.

Another valuable remark is taken from the $\mathrm{C} 2-\mathrm{H} 1$ bond length. This bond is slightly longer than the $\mathrm{C} 2-\mathrm{H}(2$ and 3$)$ bonds. This reflects the strength of the M...H1 interaction directly, which is estimated in the following order $[\mathrm{Cr}]>[\mathrm{Mo}]>[\mathrm{W}]$. This is the same sequence predicted based on the IR data. On the other hand, the differences among the $\mathrm{C} 3-\mathrm{H}$ $(4,5$ and 6$)$ bonds are negligible which confirms absence of a valuable interaction with $\mathrm{M}(\mathrm{CO})_{4}$. This description of bonding is similar to the known nature of bonding in stable transition metal carbene complexes. This subject was reviewed in a neat and comprehensive way by Frenking, Sola, and Vyboishchikov ${ }^{18}$.

The intramolecular angles are also valuable source of information. The dihedral angles $\mathrm{H} 1 \mathrm{C} 2 \mathrm{C} 1 \mathrm{M}$ are nearly equal to zero. This suggests that $\mathrm{M} \ldots \mathrm{H} 1$ is a stabilizing interaction for the molecular electron density. The value in methyl acetate is very similar, however, the 
analysis based on the energy of conformers and the NMR data will illustrate that the carbonyl oxygen...H1 interaction is not valuable. The unique differences in the angles $\mathrm{MC} 1 \mathrm{O}$ and $\mathrm{MC} 1 \mathrm{C} 2$, compared to the analogous angles in methyl acetate, indicate that the $\mathrm{M}$...H1 interaction is efficient and can cause significant distortion to achieve the ultimate stability for the electronic structures of $\left[\mathrm{M}(\mathrm{CO})_{4}(\mathrm{C}(\mathrm{OMe}) \mathrm{Me})\right]$.

Table 1. Selected bond lengths ( $\mathrm{A}$ ) and angles (angles) for the five structures.

\begin{tabular}{cccccc}
\hline Parameter & Free carbene & {$[\mathrm{Cr}]$} & {$[\mathrm{Mo}]$} & {$[\mathrm{W}]$} & MeCOOMe \\
\hline $\mathrm{C} 1-\mathrm{C} 2$ & 1.509 & 1.511 & 1.512 & 1.514 & 1.511 \\
$\mathrm{C} 1-\mathrm{O}$ & 1.316 & 1.309 & 1.312 & 1.313 & 1.354 \\
$\mathrm{C} 2-\mathrm{H} 1$ & 1.100 & 1.109 & 1.100 & 1.103 & 1.090 \\
$\mathrm{C} 2-\mathrm{H} 2$ & 1.099 & 1.096 & 1.097 & 1.096 & 1.095 \\
$\mathrm{C} 2-\mathrm{H} 3$ & 1.099 & 1.096 & 1.097 & 1.096 & 1.095 \\
$\mathrm{C} 3-\mathrm{H} 1$ & 1.092 & 1.092 & 1.091 & 1.092 & 1.093 \\
$\mathrm{C} 3-\mathrm{H} 2$ & 1.093 & 1.092 & 1.091 & 1.092 & 1.093 \\
$\mathrm{C} 3-\mathrm{H} 3$ & 1.093 & 1.089 & 1.090 & 1.090 & 1.091 \\
$\mathrm{H} 1 \mathrm{C} 2 \mathrm{C} 1 \mathrm{M}$ & - & 0.2 & 0.0 & 0.0 & 0.1 \\
$\mathrm{C} 1-\mathrm{M}$ & - & 1.891 & 2.100 & 2.079 & 1.211 \\
$\mathrm{MC} 1 \mathrm{O}$ & - & 149.6 & 140.9 & 142.3 & 123.5 \\
$\mathrm{MC} 1 \mathrm{C} 2$ & - & 97.9 & 109.4 & 107.2 & 125.8 \\
\hline
\end{tabular}

\section{Stability of conformers}

In the chromium case (Table 2), the difference in energy between the two conformers was calculated using three computational procedures. For qualitative purposes, using the two basis sets $6-31 \mathrm{G}(\mathrm{d})$ and SDD produced acceptable results. Values of $\Delta \mathrm{E}$ indicate that the interaction between $\mathrm{M}$ and $\mathrm{H} 1$ in $[\mathrm{Cr}]$ is stronger than in $[\mathrm{Mo}]$ and [W]. The order based on the energy calculations is $[\mathrm{Cr}]>[\mathrm{Mo}]>[\mathrm{W}]$, which is the same order estimated based on analyzing the structural parameters and the IR data. Conformers of methyl acetate have nearly the same stability. This result confirms that the M...H1 interaction is a stabilizing factor for their electronic structures.

Table 2. Energies (Hartrees) of conformers and the $\Delta \mathrm{E}$ in $\mathrm{kcal} / \mathrm{mol}$.

\begin{tabular}{cccc}
\hline & \multicolumn{3}{c}{ Dihedral angle $\mathrm{H} 1 \mathrm{C} 2 \mathrm{C} 1 \mathrm{M}(\mathrm{O})$} \\
\cline { 2 - 4 } & $\sim$ zero & 60 & $\Delta \mathrm{E}$ \\
\hline Free carbene & -193.046440 & -193.049725 & -2.1 \\
MeCOOMe & -268.388490 & -268.387740 & +0.5 \\
{$[\mathrm{Cr}]$} & -732.807096 & -732.797580 & +6.0 \\
& $-1690.886629^{\mathrm{a}}$ & -1690.874226 & +7.8 \\
& $-1691.171853^{\mathrm{b}}$ & -1691.160172 & +7.3 \\
{$[\mathrm{Mo}]$} & -714.063559 & -714.059607 & +2.5 \\
{$[\mathrm{~W}]$} & -714.360518 & -714.387740 & +3.5 \\
\hline
\end{tabular}

${ }^{a} B 3 L Y P / 6-31 G(d)$ calculations. ${ }^{b} B 3 L Y P / 6-311+G(2 d, p) / / B 3 L Y P / 6-31 G(d)$ calculations.

\section{Atomic charges}

To this date there is no standard method to compute the atomic charges. As it appears in the chemical literature regarding the organometallic complexes, both the NPA and the APT schemes have been employed to obtain a qualitative idea about atomic charges. The electronic structure of methyl acetate is very well understood, therefore, it is used here as a 
reference too. Both NPA and APT schemes produced, qualitatively, acceptable values (Table 3). However, only the NPA charges will be treated in order not to over-discuss the data. In all the cases, $\mathrm{C} 1$ carry a positive charge. In the free carbene the axial $p$-orbital is empty and the atomic charge is +0.24 . In presence of metal, the charge did not change significantly $(+0.39,+0.30$, and +0.21$)$. This indicates that there is certain degree of back donation from the metal kept the atomic charge from becoming more positive. However, $\mathrm{C} 1$ is considered an electron deficient center compared to the other atoms $(\mathrm{C}, \mathrm{O}$, and $\mathrm{M})$. The trend in the atomic charges of $\mathrm{C} 1$ indicates that back donation from the metal can be arranged as the following: [W] $>[\mathrm{Mo}]>[\mathrm{Cr}]$. Electrophilicity and charge decomposition for many carbene complexes were among many of the points that were studied computationally by Frenking and Sola ${ }^{19}$ based on a method developed by Dapprich and Frenking ${ }^{20}$. Their results confirm that in all of their examples $\mathrm{C} 1$ is an electron deficient atom.

Atomic charges of H1-6 in the five cases do not change significantly. On the other hand, charges on the metal are clearly different; $[\mathrm{Cr}]=-0.97,[\mathrm{Mo}]=-0.58$, and $[\mathrm{W}]=-$ 0.29 . This trend is consistent qualitatively with the predicted back donation based on the atomic charge of $\mathrm{C} 1$. Despite the negative charge on the carbonyl oxygen in methyl acetate the energy calculations illustrated that the two conformers have nearly the same stability. This demonstrates that the M...H1 interaction is not a simple electrostatic interaction. The only explanation for this observation is existence of an overlap between a metal d-orbital and $\mathrm{C} 2-\mathrm{H} 1$, which results in stabilizing the overall molecular electron density.

Table 3. The NPA and APT atomic charges.

\begin{tabular}{cccccc}
\hline & & \multicolumn{3}{c}{ NPA } & \\
\hline Atom & Free Carbene & {$[\mathrm{Cr}]$} & {$[\mathrm{Mo}]$} & {$[\mathrm{W}]$} & $\mathrm{MeCOOMe}$ \\
\hline $\mathrm{C} 1$ & 0.24 & 0.39 & 0.30 & 0.21 & 0.82 \\
$\mathrm{C} 2$ & -0.81 & -0.76 & -0.76 & -0.76 & -0.78 \\
$\mathrm{O}$ & -0.51 & -0.48 & -0.48 & -0.48 & -0.55 \\
$\mathrm{C} 3$ & -0.31 & -0.31 & -0.31 & -0.31 & -0.33 \\
$\mathrm{H} 1$ & 0.22 & 0.25 & 0.24 & 0.24 & 0.26 \\
$\mathrm{H} 2$ & 0.26 & 0.27 & 0.27 & 0.27 & 0.26 \\
$\mathrm{H} 3$ & 0.26 & 0.27 & 0.27 & 0.27 & 0.26 \\
$\mathrm{H} 4$ & 0.21 & 0.23 & 0.23 & 0.23 & 0.22 \\
$\mathrm{H} 5$ & 0.21 & 0.23 & 0.23 & 0.23 & 0.22 \\
$\mathrm{H} 6$ & 0.22 & 0.23 & 0.23 & 0.23 & 0.22 \\
$\mathrm{M}(\mathrm{O})$ & - & -0.97 & -0.58 & -0.29 & -0.60 \\
& & & $\mathrm{APT}$ & & \\
$\mathrm{C} 1$ & 0.26 & 1.13 & 1.12 & 1.09 & 1.10 \\
$\mathrm{C} 2$ & -0.81 & -0.76 & -0.76 & -0.76 & -0.78 \\
$\mathrm{O}$ & -0.60 & -0.99 & -0.95 & -0.97 & -0.83 \\
$\mathrm{C} 3$ & 0.45 & 0.43 & 0.40 & 0.40 & 0.47 \\
$\mathrm{H} 1$ & -0.05 & 0.02 & 0.00 & 0.01 & 0.01 \\
$\mathrm{H} 2$ & 0.02 & 0.01 & 0.01 & 0.02 & 0.02 \\
$\mathrm{H} 3$ & 0.02 & 0.01 & 0.01 & 0.02 & 0.02 \\
$\mathrm{H} 4$ & -0.03 & 0.01 & 0.02 & 0.02 & 0.02 \\
$\mathrm{H} 5$ & -0.03 & 0.01 & 0.02 & 0.02 & 0.02 \\
$\mathrm{H} 6$ & 0.01 & 0.00 & 0.00 & 0.00 & 0.01 \\
$\mathrm{M}(\mathrm{O})$ & - & -1.88 & -1.72 & -1.74 & -0.668 \\
\hline & & & & &
\end{tabular}




\section{Infrared frequencies (IR)}

The stretching frequencies (Table 4) indicate that the force constant of $\mathrm{C} 1-\mathrm{O}$ in the free carbene is smaller than that in presence of metal. It indicates that the bond order increases as a result of the complexation. This is a result of lone pair donation from oxygen to the empty p-orbital on $\mathrm{C} 1$. The $\mathrm{C} 1-\mathrm{O}(\mathrm{OMe})$ overlapping in methyl acetate is the smallest, which is attributed to relatively efficient $\pi$-bond in the carbonyl. These variations in $\mathrm{C} 1-\mathrm{O}$ stretching frequencies indicate that back donation from the metal, in general, is weak and $\mathrm{C} 1$ can be viewed as an electron deficient center.

The metal caused significant differences in the force constants of $\mathrm{C} 2-\mathrm{H} 1, \mathrm{C} 2-\mathrm{H} 2$, and $\mathrm{C} 2-\mathrm{H} 3$. In addition to that, the interaction between $[\mathrm{M}]$ and $\mathrm{C} 2-\mathrm{H} 1$ weakened strength of the bond. The difference between $\mathrm{C} 2-\mathrm{H} 1$ and $\mathrm{C} 2-\mathrm{H}(2$ and 3) stretching frequencies for the three metals are: $[\mathrm{Cr}]=124 \mathrm{~cm}^{-1}$, $[\mathrm{Mo}]=65 \mathrm{~cm}^{-1}$ and $[\mathrm{W}]=79 \mathrm{~cm}^{-1}$. These values indicate that strength of the M...C2-H1 interaction has the following order $[\mathrm{Cr}]>[\mathrm{W}]>[\mathrm{Mo}]$. Force constants of $\mathrm{C} 2-\mathrm{H}(1,2$, and 3$)$ in methyl acetate are identical, which indicates that the interaction with $\mathrm{H} 1$ exist only in $[\mathrm{M}]$ and does not exist between $\mathrm{H} 1$ and the carbonyl oxygen of methyl acetate.

On the other hand, the stretching frequencies of $\mathrm{C} 3-\mathrm{H}(4,5$ and 6$)$ are identical in each case of the $[\mathrm{M}]$ species. This demonstrates that there is negligible interaction between these protons and the metal or the carbonyl group. In general, analysis of the IR data is consistent with the structural parameters, stability of conformers, and the atomic charges.

Table 4. Selected infrared frequencies, $\mathrm{cm}^{-1}$.

\begin{tabular}{cccccc}
\hline Bond & Free Carbene & {$[\mathrm{Cr}]$} & {$[\mathrm{Mo}]$} & {$[\mathrm{W}]$} & $\mathrm{MeCOOMe}$ \\
\hline C1-C2 & 1021 & 1022 & 1030 & 1024 & - \\
C1-O & 1327 & 1376 & 1349 & 1356 & 1290 \\
C2-H1 & 3012 & 2952 & 3022 & 3001 & 3071 \\
C2-H2 & 3012 & 3076 & 3087 & 3080 & 3071 \\
C2-H3 & 3012 & 3076 & 3087 & 3080 & 3071 \\
C3-H4 & 3068 & 3089 & 3089 & 3086 & 3074 \\
C3-H5 & 3068 & 3089 & 3089 & 3086 & 3074 \\
C3-H6 & 3068 & 3089 & 3089 & 3086 & 3074 \\
\hline
\end{tabular}

NMR Chemical Shifts $\left({ }^{1} \mathrm{H}\right.$ and $\left.{ }^{13} \mathrm{C}\right)$

In general, $\mathrm{C} 1$ is de-shielded and is considered electron deficient (Table 5), as predicted by the NPA scheme. Bonding to the metal caused a decrease in its chemical shift with respect to the free carbene. This change indicates that there is a certain degree of back donation from the metal, but, it is considered weak compared to the $\pi$-bond of the carbonyl in methyl acetate.

On the other hand and surprisingly, $\mathrm{C} 2$ became more electron rich center. In other words, bonding to the metal increased the electron density. In case of chromium compared to the other two metals, there is an extraordinary change in the chemical shift (51 ppm). This result is consistent with the energy calculations of the conformers and indicates that the overlap between the $d$-orbital of chromium with $\mathrm{C} 2-\mathrm{H} 1$ is the most efficient (Figure 3 ). This is consistent with the orbital interaction theory ${ }^{21}$, that an electron rich center ( $\sigma$-bond of $\left.\mathrm{C} 2-\mathrm{H} 1\right)$ can interact with empty orbital ( $d$-orbital of $[\mathrm{M}])$. Also, this result does not disagree with the fact that the alpha protons of carbene are acidic ${ }^{22}$. As a result of this overlapping shielding the nucleus (H1) increased and the chemical shift decreased (Table 5). The H-NMR data for $\mathrm{H} 1, \mathrm{H} 2$, and $\mathrm{H} 3$ are consistent with the observed changes for $\mathrm{C} 2$. Chemical shifts of C3, H4, H5, and $\mathrm{H} 6$ are small which is consistent with the IR data. 
Table 5. The ${ }^{13} \mathrm{C}$ - and ${ }^{1} \mathrm{H}-\mathrm{NMR}$ chemical shifts (ppm).

\begin{tabular}{cccccc}
\hline Atom & Free Carbene & {$[\mathrm{Cr}]$} & {$[\mathrm{Mo}]$} & {$[\mathrm{W}]$} & $\mathrm{MeCOOMe}$ \\
\hline C1 & 440 & 317 & 326 & 303 & 161 \\
C2 & 44 & -7 & 16 & 10 & 20 \\
C3 & 71 & 65 & 65 & 64 & 51 \\
H1 & 2.1 & -0.8 & 1.4 & 1.0 & 2.1 \\
H2 & 3.3 & 0.5 & 1.2 & 1.0 & 2.6 \\
H3 & 3.3 & 0.5 & 1.2 & 1.0 & 2.6 \\
H4 & 4.8 & 4.7 & 4.5 & 4.3 & 4.3 \\
H5 & 4.8 & 4.7 & 4.5 & 4.3 & 4.3 \\
H6 & 4.9 & 4.7 & 4.7 & 4.5 & 3.9 \\
\hline
\end{tabular}

New antibonding orbital

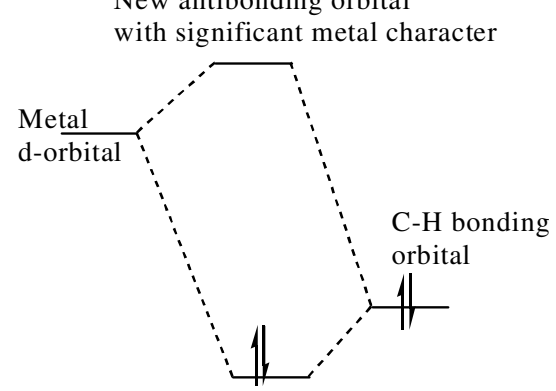

Significant

C-H character

Figure 3. Simplified molecular orbitals representation for the $[\mathrm{M}] \ldots \mathrm{C} 2-\mathrm{H} 1$ interaction.

\section{Conclusion}

Analysis of the data revealed that bonding the carbene $\mathrm{C}(\mathrm{OMe}) \mathrm{Me}$ to $\mathrm{M}(\mathrm{CO})_{4}(\mathrm{M}=\mathrm{Cr}, \mathrm{Mo}, \mathrm{W})$ causes dramatic changes in many of the theoretical organic aspects; the structure, relative stability of conformers, atomic charges, infrared frequencies, and ${ }^{1} \mathrm{H}-$ and ${ }^{13} \mathrm{C}-\mathrm{NMR}$ chemical shifts. The results from these aspects illustrate a unique case of $[\mathrm{M}] \ldots \mathrm{C} 2-\mathrm{H} 1$ interaction. Although this interaction weakens the $\mathrm{C} 2-\mathrm{H} 1$ bond but it causes an overall stability for the electronic structure of the molecule. In general, the greater effect from chromium is attributed to the shorter $\mathrm{Cr}-\mathrm{C} 1$ distance. This is a new addition to the "Orbital Interaction Theory" ${ }^{21}$ and to the literature information about the organic/organometallic reactive intermediates. This type of stabilizing interaction is known in the chemical literature and is called "agostic interaction"

\section{Acknowledgment}

Special thanks are due to Al-Hussein Bin Talal University for the generous support through the research grant (2008/78).

\section{References}

1. Dötz K H, Angew Chem., 1975, 87, 672.

2. Gleichmann M M, Dötz K H and Hess B A, J Am Chem Soc., 1996, 118, 10551.

3. Casey C P, Reactive Intermediates, Ed. Jones M Jr and Moss R A, New York: Wiley, 1981, 2, 155.

4. Torrent M, Duran M and Solà M, Organometallics, 1998, 17, 1492. 
5. Torrent M, Duran M and Solà M, J Am Chem Soc., 1999, 121, 1309.

6. Fischer H and Hofmann P, Organometallics, 1999, 18, 2590.

7. Barluenga J, Aznar F, Gutierrez I, Martin A, Garcia-Granda S and Llorca-Baragano M A, J Am Chem Soc., 2000, 122, 1314.

8. Irshaidat T, Tetrahedron Lett., 2008, 49, 5894.

9. Zhang $\mathrm{Y}$, Irshaidat $\mathrm{T}$, Wang $\mathrm{H}$, Waynant $\mathrm{KV}$, Wang $\mathrm{H}$ and Herndon $\mathrm{J} \mathrm{W}, J$ Organomet Chem., 2008, 693, 3337.

10. Irshaidat T, J Mol Struct (Theochem)., 2009, 897, 154.

11. Lee C, Yang W and Parr R G, Phys Rev B., 1998, 37, 785.

12. Frisch M J, et al. Gaussian 03, Revision, Gaussian Inc., Wallingford CT, 2004.

13. Hehre W J, Ditchfield R and Pople J A, J Chem Phys., 1971, 56, 2257.

14. Wedig U, Dolg M, Stoll H and Preuss H, Quantum Chemistry, The Challenge of Transition Metals and Coordination Chemistry, Ed. Veillard A, The Netherlands: Reidel, Dordrecht, 1986, 79.

15. Cioslowski J, J Am Chem Soc., 1989, 111, 8333.

16. Reed A E, Curtiss L A and Weinhold F, Chem Rev., 1988, 88, 899.

17. Ruud K, Helgaker T, Bak K L, Jørgensen P and Jensen H J A, J Chem Phys., 1993, 99, 3847.

18. Frenking G, Sola` M and Vyboishchikov S F, J Organomet Chem., 2005, 690, 6178.

19. Cases M, Frenking G, Duran M and Sola M, Organometallics, 2002, 21, 4182.

20. Dapprich S and Frenking G, J Phys Chem., 1995, 99, 9352.

21. Rauk A, Second Edition, New York: Wiley, 2001.

22. Bernasconi C F, Leyes A E, Ragains M L, Shi Y, Wang H and Wulf W D, J Am Chem Soc., 1998, 120, 8632.

23. Clot E and Eisenstein O, Structure and Bonding, 2004, 113, 1. 


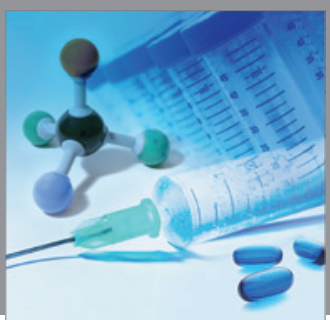

International Journal of

Medicinal Chemistry

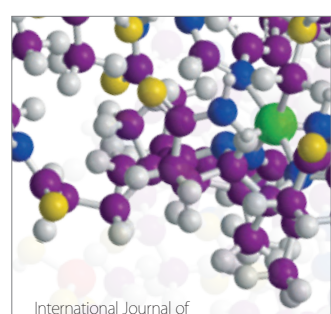

Carbohydrate Chemistry

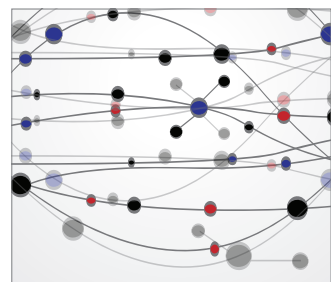

The Scientific World Journal
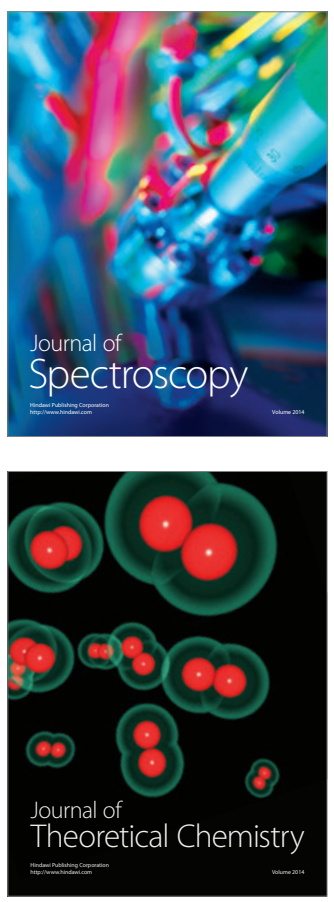
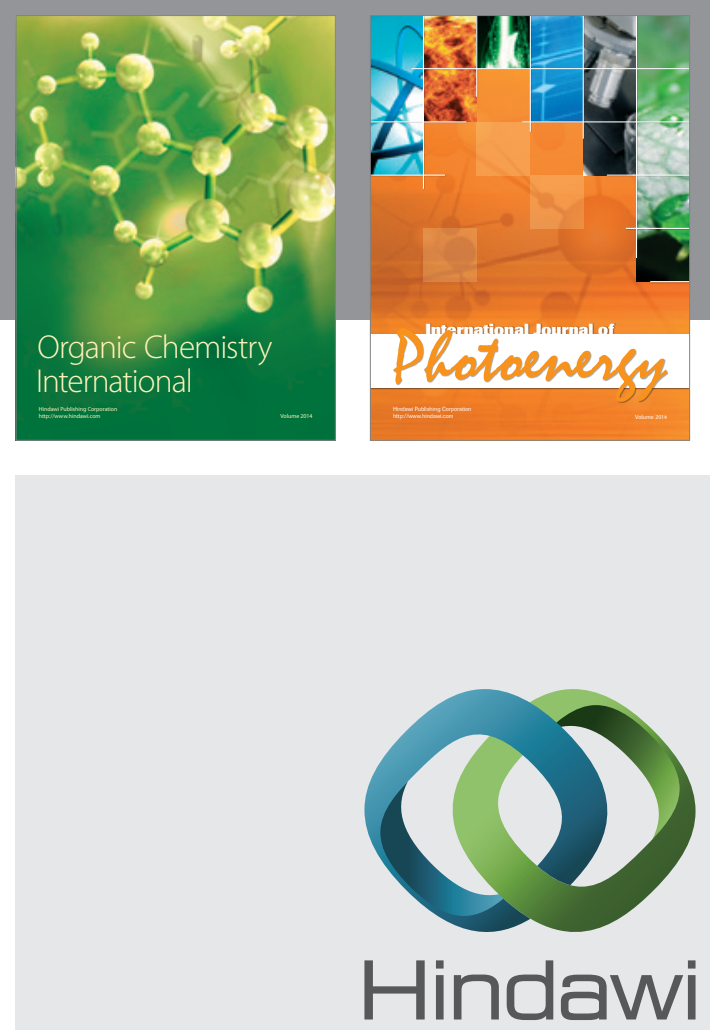

Submit your manuscripts at

http://www.hindawi.com
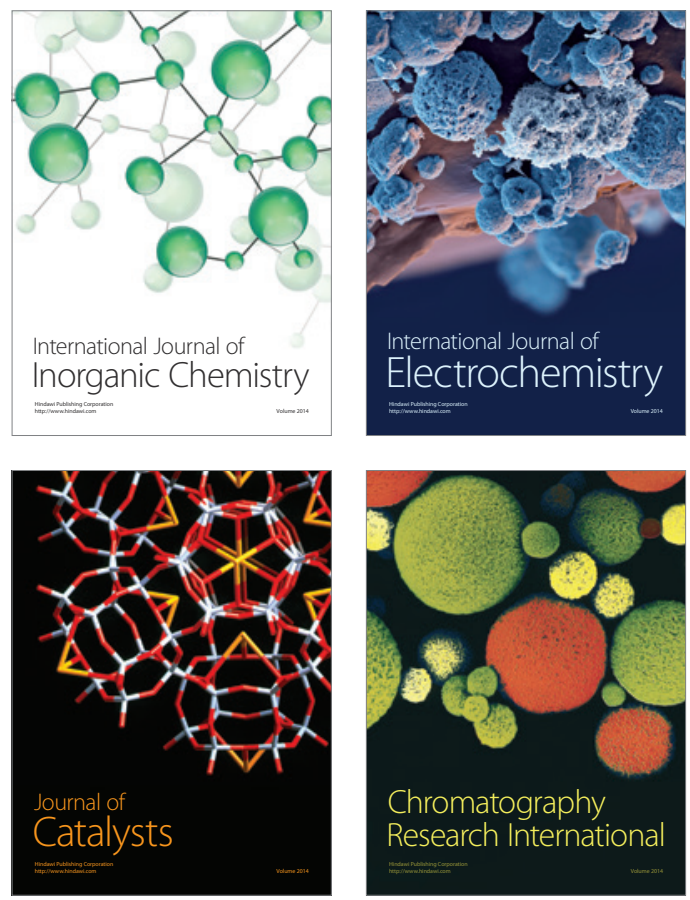
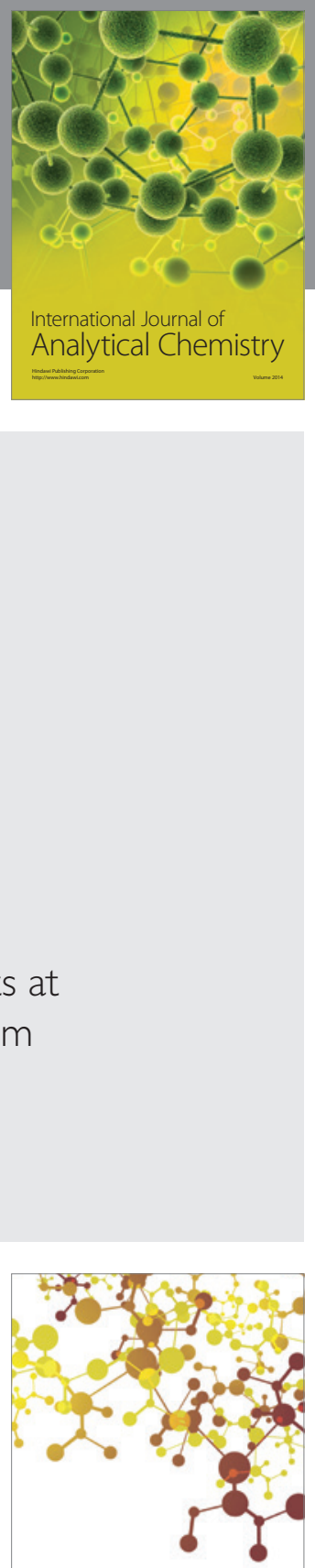

Journal of

Applied Chemistry
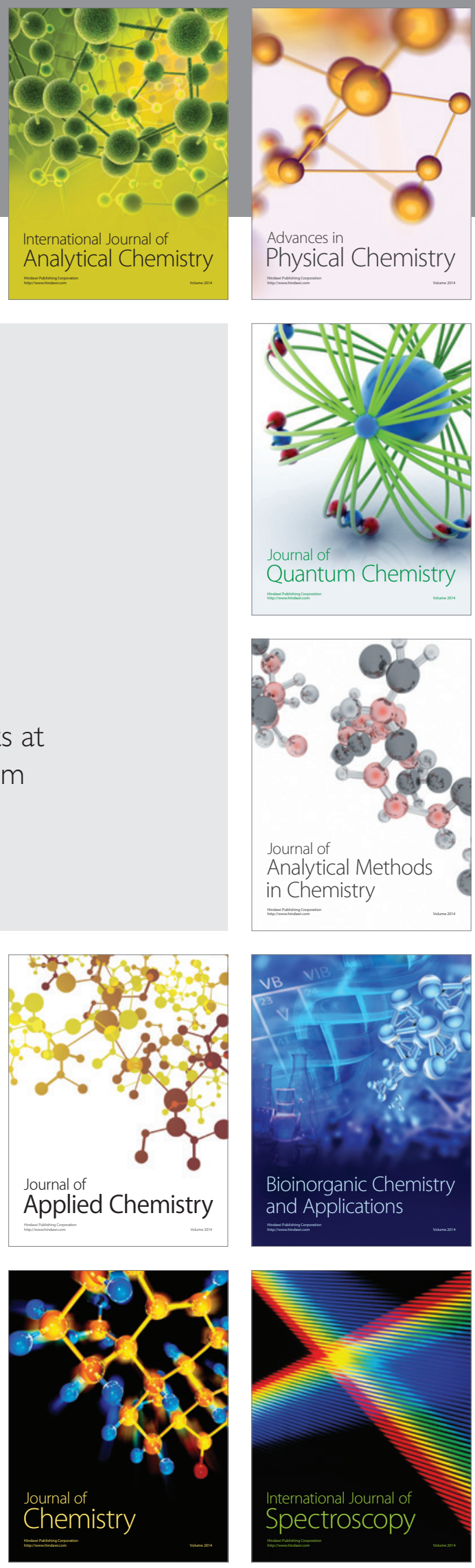